\title{
FETAL OUTCOME IN UNBOOKED POSTDATED PREGNANCY
}

\author{
MUSTAFA FN ${ }^{1}$, YASMIN N ${ }^{2}$, AFREEN N $^{3}$, SATTAR K ${ }^{4}$, NAHAR A ${ }^{5}$, NAHAR N ${ }^{6}$
}

\begin{abstract}
:
Background: People always complain that previously almost all women used to have vaginal delivery, but they do not mention the fetal outcome, eg, the number of affected fetus and also intrauterine death or stillborn. The objective of our study was to see the fetal outcome among antenatally unbooked women with gestational age beyond EDD who came to hospital with labor pain and also to see the mode of delivery in these pregnancies.
\end{abstract}

Method: It was an observational prospective study conducted in Daudkandi Upazilla Health Complex, Kumilla, from March, 2012 to May, 2012. Sampling procedure was consecutive sampling. A total number of 52 postdated pregnant women were enrolled in our study who came to hospital with labor pain.

Result: The percentage of vaginal delivery in postdated pregnancy was $80.77 \%$ and the percentage of cesarean delivery was $19.23 \%$. Fetal outcome was good in $76.92 \%$, baby was asphyxiated in $19.23 \%$, baby was stillborn in $3.85 \%$ women.

Conclusion: Though vaginal delivery rate is high in women with antenatally unbooked postdated pregnancy with spontaneous onset of labour pain, but the fetal outcome is not good. The women who are crossing EDD must undergo careful fetal monitoring to have more vaginal delivery with good fetal outcome.

Key Words : Unbooked Pregnancy, Postdated Pregnancy, Fetal asphyxia.

J Dhaka Med Coll. 2018; 27(1) : 47-50

\section{Introduction}

Postdated pregnancy is a very important feature in obstetric patients. Accurate estimation of gestational age is vital in pregnant women. The duration of pregnancy has been calculated from the first day of last menstrual period in terms of ten lunar months or nine calendar months and seven days or 280 days or 40 weeks. This is called menstrual or gestational age ${ }^{1}$. Here the calculated date is called Expected Date of Delivery (EDD).

A postdated pregnancy is the one which extends beyond 40 completed weeks or 280 days from the first day of the LMP and has an incidence of $4-14 \% .^{2} \mathrm{~A}$ post-term pregnancy is the one which extends beyond 42 completed weeks or 294 days from the first day of the LMP and has an incidence of $5-10 \% .^{3}$
Accurate pregnancy dating is critical to the diagnosis of post-term birth. Routine use of ultrasound to confirm pregnancy dating can decrease occurrence of post-term birth. ${ }^{4}$ Common risk factors for post-term birth include obesity, nulliparity and prior post-term birth and rare causes include placental sulphatase deficiency (an X-linked recessive disorder characterized by low estriol levels), fetal adrenal hypoplasia or insufficiency and trisomy 16 and 18. ${ }^{5,6}$

In postdated pregnancy there are chances of fetal hypoxia, asphyxia, intracranial damage, meconium aspiration syndrome, macrosomia, hypoglycemia and still births. These perinatal risks increase in the gestational age beyond 40 weeks. ${ }^{7,8}$

1. Dr. Fahmida Naz Mustafa, Assistant Professor, Obs and Gynae Deptt, Mugda Medical College, Dhaka.

2. Prof. Nahid Yasmin, Head of the department, Department of Obs nad Gynae, Mugda Medical College

3. Dr. Nasreen Afreen, Assistant Professor, Mugda Medical College

4. Dr . Kamrun Sattar, Senior Consultant, Kumilla General Hospital, Kumilla

5. Dr. Aftabun Nahar, Associate Professor, Mugda Medical College, Dhaka

6. Dr. Nazmun Nahar, Associate Professor, National Institute Of Neurosciences, Dhaka.

Correspondence : Dr. Fahmida Naz Mustafa, Assistant Professor, Obs and Gynae Deptt, Mugda Medical College, Mugda, Dhaka.Email : nazf04@yahoo,com Mobile : 01715038881

Received: 21 July 2017

Revision: 01 September 2017

Accepted: 15 September 2017

DOI: http://dx.doi.org/10.3329/jdmc.v27i1.38945 
The maternal risks include an increase in labor dystocia, an increase in severe perineal injury related to macrosomia and operative vaginal delivery and an increase in the rate of cesarean delivery and postpartum haemorrhage..$^{9,10}$

Cesarean section rate has increased recently in Bangladesh. People often complain that previously vaginal delivery occurred in large amount, why now cesarean section rate has increased so high? These days many of the pregnancies do not go upto Expected Date of Delivery and are terminated earlier due to various maternal and fetal causes. If pregnancy extends upto and beyond EDD, there are more chances of initiation of spontaneous labour pain and vaginal delivery, but in some cases fetuses are compromised if not monitored properly.

\section{Objectives of the study:}

The objective of the study was to see the fetal outcome among antenatally unbooked women with gestational age beyond EDD who came to hospital with labor pain and also to see the mode of delivery in these pregnancies.

\section{Inclusion Criteria:}

- All pregnant women with gestational age beyond Expected Date of Delivery.

- The women came with labor pain.

- The women did not have regular antenatal check up.

\section{Exclusion Criteria:}

- Pregnant women whose gestational age did not cross EDD.

- Pregnant women who did not have labor pain.

- Pregnant women who had regular antenatal check up.

\section{Materials and methods :}

It was an observational prospective study conducted in Daudkandi Upazilla Health Complex, Kumilla, from March, 2012 to May, 2012. Sampling procedure was consecutive sampling.

A total number of 52 pregnant women were enrolled in our study who came to the hospital with labor pain from March to May of 2012.
Gestational age crossed EDD in all pregnancy. An informed consent was taken from all women who fulfilled inclusion criteria. There was no age limit. All relevant data regarding obstetric history was taken.

The patients were assessed clinically and where needed augmentation of labor was done. Some patients delivered per vaginally and some underwent cesarean section. We calculated the proportion of vaginal and cesarean delivery and fetal outcome among these women. We wanted to see the mode of delivery and fetal outcome in women who did not have any antenatal intervention.

\section{Result :}

$50 \%$ of pregnant women in our study was in 21 -30 yrs of age group, $40.38 \%$ was in less than or upto 20 yrs of age and $9.62 \%$ was in above $30 \mathrm{yrs}$ of age group.

$73.08 \%$ women were in middle socioeconomic status, $26.92 \%$ were in lower socioeconomic status, none were in upper socioeconomic status.

$59.62 \%$ women were primigravida and $40.38 \%$ were multigravida.

Gestational period of $44.23 \%$ women were within $40-41$ weeks, $40.38 \%$ were of $41-42$ weeks, $15.39 \%$ were from more than 42 weeks of gestational period.

The percentage of vaginal delivery in postdated pregnancy was $80.77 \%$ and the percentage of cesarean delivery was $19.23 \%$.

Fetal outcome was good in $76.92 \%$, baby was asphyxiated in $19.23 \%$, baby was stillborn in $3.85 \%$ women.

Table-I

Age distribution of patients:

\begin{tabular}{lcc}
\hline Age (years) & $\begin{array}{c}\text { Number of } \\
\text { patients }\end{array}$ & $\begin{array}{c}\text { Percentage of } \\
\text { patients }\end{array}$ \\
\hline$>20$ & 21 & $40.38 \%$ \\
$21-30$ & 26 & $50 \%$ \\
$>30$ & 5 & $9.62 \%$ \\
\hline
\end{tabular}


Table-II

Socioeconomic condition:

\begin{tabular}{lcc}
\hline $\begin{array}{l}\text { Socioeconomic } \\
\text { status }\end{array}$ & $\begin{array}{c}\text { Number of } \\
\text { patients }\end{array}$ & $\begin{array}{c}\text { Percentage } \\
\text { of patients }\end{array}$ \\
\hline Upper & 00 & $0 \%$ \\
Middle & 38 & $73.08 \%$ \\
Poor & 14 & $26.92 \%$ \\
\hline
\end{tabular}

Table-III

Parity distribution:

\begin{tabular}{lcc}
\hline Parity & $\begin{array}{c}\text { Number } \\
\text { of patients }\end{array}$ & $\begin{array}{c}\text { Percentage } \\
\text { of patients }\end{array}$ \\
\hline Primigravida & 31 & $59.62 \%$ \\
Multigravida & 21 & $40.38 \%$ \\
\hline
\end{tabular}

Table-IV

Gestational period distribution:

\begin{tabular}{lcc}
\hline Gestational period & $\begin{array}{c}\text { N3umber } \\
\text { of patients }\end{array}$ & $\begin{array}{c}\text { Percentage } \\
\text { of patients }\end{array}$ \\
\hline $40-41$ weeks & 23 & $44.23 \%$ \\
$41-42$ weeks & 21 & $40.38 \%$ \\
$>42$ weeks & 08 & $15.39 \%$ \\
\hline
\end{tabular}

Table-V

Mode of delivery

\begin{tabular}{lcc}
\hline Mode of delivery & $\begin{array}{c}\text { Number } \\
\text { of patients }\end{array}$ & $\begin{array}{c}\text { Percentage } \\
\text { of patients }\end{array}$ \\
\hline Vaginal delivery & 42 & $80.77 \%$ \\
LUCS & 10 & $19.23 \%$ \\
\hline
\end{tabular}

Table-VI

Perinatal outcome

\begin{tabular}{lcc}
\hline Perinatal outcome & $\begin{array}{c}\text { Number } \\
\text { of babies }\end{array}$ & $\begin{array}{c}\text { Percentage } \\
\text { of babies }\end{array}$ \\
\hline $\begin{array}{l}\text { Good APGAR score } \\
\text { (7-10/1min and }\end{array}$ & 40 & $76.92 \%$ \\
at 5 min) & & \\
Asphyxia & 10 & $19.23 \%$ \\
Stillborn & 2 & $3.85 \%$ \\
\hline
\end{tabular}

\section{Discussion:}

We studied postdated pregnant women with labor pain in an upazilla health complex of Bangladesh. These women did not have regular antenatal check up and were of middle and lower socioeconomic status. We studied these women because we wanted to see the fetal outcome in these pregnancies. We also evaluated at what gestational period the postdated women spontaneously went to labour and their mode of delivery. These days in all institutions and also in personal practices rate of cesarean section has risen. People often make query that previously women delivered vaginally, why now these days cesarean section rate rose so high? Actually during antenatal checkup many obstetric complications and fetal compromisation are found and pregnancy may not reach Expected Date of Delivery and termination may be required before EDD, since fetal outcome is very important in present obstetric practices. So, we studied to find out the mode of delivery and fetal outcome in those women who did not have regular antenatal checkup and did not have any antenatal intervention prior to spontaneous onset of labor pain.

In a study done in $\mathrm{DMCH}$ and published in 2010 , it was seen that in postdated pregnancy where $74 \%$ cases needed induction of labor either by oxytocin or prostaglandin, cesarean section was done in $44 \%$ cases including all study women requiring or not requiring induction of labor. But in our study where women came with spontaneous onset of labor pain only $19.23 \%$ required cesarean section. In the former study, there was no stillborn baby and only $6 \%$ babies were asphyxiated. But in our study, $19.23 \%$ babies were asphyxiated and $3.85 \%$ babies were stillborn.

In another study, done in Jalalabad Ragib Rabeya Medical College Hospital, Sylhet , published in 2009, in postdated pregnancy $42 \%$ needed cesarean section after induction of labour and $58 \%$ had vaginal delivery. In this group, neonatal outcome was very satisfactory, no baby was asphyxiated or stillborn.

Around the world, cesarean section rates have increased dramatically, something that has 
proven controversial as a large amount of them are not medically required. The growing cesarean section rate can be attributed to many factors including women's personal preference also. Sweden is a notable example with $16.4 \%$ sections for every 100 live births. Turkey is at the opposite end of the scale with just over half of all babies delivered via cesarean section. The United States and Australia also have higher cesarean section rates than average, $32.5 \%$ and $32.1 \%$ respectively in 2013 .

Between 2004 and 2014 the cesarean section rate in Bangladesh increased from 4 to $23 \%$. Some experts put the current rate at over 30\% (Friday, 25 August 2017, published by Save The Children).

With all the above discussion, we have seen that though vaginal delivery rate is high in our study where intervention was less in antenatal period but fetal outcome was not very good.

Limitation: The study does not have a control group.

\section{Conclusion:}

Though now a days much criticism is done regarding mode of delivery and people always mention that previously women had vaginal delivery more but they don't mention fetal outcome. In our study we found that if women who crossed EDD and spontaneously started labor pain, vaginal delivery rate was much high in those cases. But on the contrary, fetal outcome is not good. A significant number of babies sufferred birth asphyxia and few babies were stillborn. So, though vaginal delivery rate is high in women with antenatally unbooked postdated pregnancy with spontaneous onset of labour pain, but the fetal outcome is not good. The women who are crossing EDD must undergo carefull fetal monitoring to have more vaginal delivery with good fetal outcome.

\section{References:}

1. Hiralal Konar, Diagnosis of Pregnancy, , DC Dutta's Textbook of Obstetrics, eighth edition, 2015 , page 73.

2. F. Fachinetti, V. Vaccaro, Unit of Gynecology and Obstetrics, Mother-Infant Department, University of Modena and Reggio Emilia, Modena, Italy.

3. Gary F Cunningham, Steven L Bloom, Catherine Y Spong, et al. Post term pregnancy. Williams Obstetrics, 24 ${ }^{\text {th }}$ edn., McGraw-Hill, Medical publication Division, USA, 2014: 862-871pp.

4. Caughey AB, Snegovskikh VV, Norwitz ER. Post-term pregnancy: how can we improve outcomes? ObstetGynecolSurv 2008;63:715-24.

5. Norwitz ER, Snegovskikh VV, Caughey AB. Prolonged pregnancy: when should we intervene? ClinObstetGynecol 2007;50:547-57.

6. Roos N, Sahlin L, Ekman-Ordeberg G, Kieler H, Stephansson O. Maternal risk factors for post-term pregnancy and cesarean delivery following labor induction. ActaObstetGynecolScand 2010;89:100310 .

7. Caughey AB, Washington AE, Laros RK Jr. Neonatal complications of term pregnancy: rates by gestational age increase in a continuous, not threshold, fashion. Am J Obstet Gynecol.2005;192(1):185-90.

8. Heimstad R, Romundstad PR, Salvesen KA. Induction of labour for postterm pregnancy and risk estimates for intrauterine and perinatal death.Acta Obstet Gynecol Scand.2008;87(2):247-9.

9. Caughey AB, Stotland NE, Washington AE. Maternal and obstetric complications of pregnancy are associated with increasing gestational age at term. Am J Obstet Gynecol. 2007;196(2):155.e1-6.

10. Caughey AB, Nicholson JM, Cheng YW, et al. Induction of labor and cesarean delivery by gestational age. Am J Obstet Gynecol. 2006; 195(3):700-5. 